\title{
Coaching revisitado
}

Coletânea destaca o papel do coaching como instrumento que desenvolve competências individuais e organizacionais. 0 livro apresenta uma série de usos dessa ferramenta em instante no qual as empresas se tornam sistemas cada vez mais complexos eos indivíduos são chamados a se responsabilizarem por suas carreiras.

Por Bruno Profeta Guimarães Reciprhocal

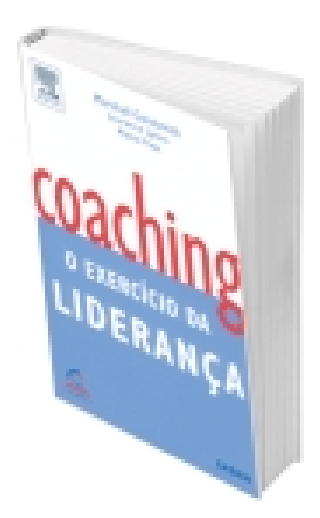

Coaching: o Exercício da Liderança Marshall Goldsmith, Laurence Lyons e Alyssa Freas Elsevier-Campus, 2004

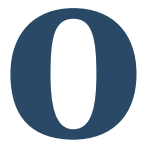

mundo dos esportes parece ter invadido o mundo dos negócios. É cada vez mais comum o uso de termos trazidos das práticas esportivas na gestão de pessoas, tais como performance, time, competição, e, já há algum tempo, coaching e coacher. Coaching diz respeito à prática de desenvolvimento de competências individuais ou grupais que se baseia em uma abordagem "sob medida"; coacher refere-se ao agente que conduz a prática do coaching, 0 equivalente ao técnico de uma equipe esportiva, transposto para a figura do gestor.

No livro Coaching: o Exercício da Liderança, o leitor encontrará uma abordagem interdisciplinar sobre 0 termo coaching e suas (possíveis) aplicações no contexto da gestão de pessoas. A obra do trio liderado por Marshall Goldsmith reúne quarenta colaboradores de alto nível envolvidos com o processo de coaching, desde conselheiros de executivos até acadêmicos e pesquisadores. 0 livro traz figuras de renome como Edgar Schein, Dave Ulrich, James Belasco e Paul
Hersey, além de Elizabeth e Gifford Pinchot.

O objetivo da obra não é apenas compilar diferentes visões sobre o coaching como uma técnica a mais na caixa das ferramentas gerenciais, mas consolidar e posicionar o tema como modelo de liderança e estilo de gestão em tempos de intensa turbulência e estressante instabilidade emocional e material. Parte-se do pressuposto de que o coaching deve estar inserido nos processos de gestão como componente estratégico, que traz benefícios às organizações e aos indivíduos.

O livro está estruturado em cinco partes. Na primeira, Fundamentos do Coaching, encontramos artigos que tratam dos elementos e características essenciais do conceito, ap resentado como estilo de trabal ho adequado à era da "Iiderança pós-gerencial". Na segunda parte, Papel e Identidade, o foco está nos indivíduos que se dedicam à prática do coaching, quais são os papéis assumidos no dia-a-dia de coachers e líderes. $\mathrm{Na}$ terceira parte, Momentos e Transições, os autores abordam a relação entre coaching e mudança organi- 
zacional, el egendo a situação transformacional como contexto inerente ao trabalho de coaching. A quarta parte, Práticas e Técnicas, oferece um detaIhamento de práticas experimentadas e testadas em campo, seus êxitos e armadilhas. Finalmente, na última parte do livro, Expansão das Situações, a análise se volta para o diferencial que o processo de coaching oferece na obtenção de resultados.

Recomendamos a leitura deste livro a profissionais de recursos humanos e gerentes interessados em compreender melhor a complexidade e amplitude de sua atividade. Em primeiro lugar, porque o livro tem um estilo diferente de outros sobre 0 assunto, especialmente por sua abordagem séria e fundamentada. Em segundo, porque considera o coaching como uma atividade complexa que envolve (potenciais) novas formas de relacionamento chefe-subordinado. Tal relação, em contrapartida, exige uma profunda compreensão da natureza humana e da dificuldade de criar líderes equilibrados, que conseguem, ao mesmo tempo, se desenvolver e também desenvolver as pessoas que estão à sua volta.

0 coacher é, na verdade, uma adaptação recente do papel do líder. $\mathrm{Na}$ era moderna, por exemplo, o líder ideal era aquele que usava princípios racionais para gerir, focando exclusivamente a produção e tendo uma postura neutra ou fria em relação a seus subordinados. Hoje, o líder ideal é um "líder simbólico", que consegue gerar a adesão de seus liderados por meio de processos identificatórios, e não com base na força ou no poder que emana formalmente de seu cargo. Essa nova exigência traz aos líderes desafios inéditos, e as situações do dia-a-dia mostram que nem sempre eles estão preparados para lidar com a complexidade e as contradições envolvidas em seu papel. 0 coaching pode ser visto aqui como uma ferramenta oportuna de desenvolvimento e ajuda para que os líderes respondam à altura das exigências que hoje Ihe são feitas.

$M$ ais do que enfatizar, irreal isticamente, o papel do líder e do coaching, este livro aborda os limites do que é possível nesse terreno irregular do relacionamento e desenvolvimento humanos. 0 leitor deve lê-lo a partir de uma perspectiva realista, vendo-o como um conjunto de subsídios que podem contribuir para tornar o papel do líder mais coerente com esses novos tempos de el evada incerteza e complexidade.

Bruno Profeta Guimarães

Psicólogo graduado pela USP

Consultor da Reciprhocal

E-mail: bruno@reciprhocal.com.br 